\title{
Psicanálise e ideologia: a violência da representação
}

(Psychoanalysis and ideology: the violence of representation)

(Psicoanálisis e ideología: la violencia de la representación)

Antônio M. R. Teixeira*

\begin{abstract}
Resumo
$\mathrm{O}$ artigo trata do problema examinado pelo ensaísta alemão Walter Benjamin, em "Por uma crítica da violência", relativo à submissão violenta da linguagem, em seu uso instrumental representativo, assim como dos impasses relativos à crítica da ideologia, na perspectiva do materialismo histórico e da psicanálise. Esses impasses estão referidos à impossibilidade de se tratar da violência da representação fora de um discurso representativo, como também à ausência de um observatório externo à ideologia ou de um lugar extraideológico desde onde uma crítica da ideologia poderia exercer-se. Nessa abordagem, procurou-se explicitar os meios que a psicanálise oferece para se pensar a violência ideológica da representação mediante um tratamento conceitual da dimensão da exceção soberana.
\end{abstract}

Palavras-chave: psicanálise; violência; representação; ideologia; exceção.

\begin{abstract}
The article deals with the problem examined by German essayist Walter Benjamin, in "Towards a Critique of violence", reported to the violent submission of language in its instrumental representative use, as well as the impasses of the critique of ideology, from the perspective of historical materialism and psychoanalysis. These impasses are referred to the impossibility of dealing with the violence of representation out of a representative discourse, besides the absence of an external observatory or an extra-ideological place from which a critique of ideology could be performed. In this approach, we tried to clarify the ways psychoanalysis offers to think violence ideological representation through a conceptual approach of the sovereign exception.
\end{abstract}

Key-words: psicoanálisis; violence; representation; ideology; exception.

Texto recebido em outubro de 2009 e aprovado para publicação em novembro de 2009.

* Doutor em Psicanálise (Champ Freudien - Paris VIII), professor associado da Faculdade de Filosofia e Ciências Humanas da Universidade Federal de Minas Gerais - UFMG. E-mail: amrteixeira@uol.com.br. 


\section{Resumen}

El artículo trata del problema examinado por el ensayista alemán Walter Benjamin, en "Para una crítica de la violencia", relativo a la sumisión violenta del lenguaje, en su uso instrumental representativo, así como de los puntos muertos relativos a la crítica de la ideología, en la perspectiva del materialismo histórico y del psicoanálisis. Esos puntos muertos se refieren a la imposibilidad de tratar la violencia de la representación fuera de un discurso representativo, así como también a la ausencia de un observatorio externo a la ideología o de un lugar extra-ideológico en el que se podría ejercer una crítica de la ideología. En ese enfoque, se procuró explicitar los medios que el psicoanálisis ofrece para que se pueda pensar la violencia ideológica de la representación mediante un tratamiento conceptual de la dimensión de la excepción soberana.

Palabras-clave: psicoanálisis; violência; representación; ideologia; excepción.

Normalmente não se nota a dificuldade por não se pensar no geral com paixão, porém com superficialidade cômoda. A exceção, ao contrário, pensa o geral com paixão enérgica (Schmitt, 2006).

\section{Introdução}

or ocasião de uma conferência apresentada em Los Angeles, no colóquio intitulado "O nazismo e a solução final: os limites da representação", Jacques Derrida se interrogava, em estilo proléptico, pelo que W. Benjamin teria podido pensar a respeito do nazismo e da solução final, caso a evolução desse mesmo acontecimento não o tivesse tirado tão precocemente de cena (Derrida, 2007, p. 61-134). Alguns meses mais tarde, ele afirmaria, num postscriptum dedicado à mesma conferência, que, ao menos em tese, Benjamin já antecipara o que estaria por vir. Ao enunciar que o horror da solução final desafiava a própria representabilidade, Derrida verificou que sua ocorrência procedia justamente daquilo que constituía, para W. Benjamin, o pecado original do espírito linguístico, com a queda (Sundenfall) da linguagem na função de representação (Benjamin, 1988, p. 23 e passim).

Se for, pois, verdade, para Benjamin, que o mal advém à linguagem pela via da dimensão representativa, pela via, portanto, técnica e utilitária que arrasta a linguagem para fora de sua destinação originária de expressão e nomeação, essa radicalização do mal, ligada à queda na linguagem da representação, terá encontrado no nazismo seu maior alcance. Seu programa 
é a figura mais marcante da violência midiática e da exploração política das técnicas representativas, conforme se atesta, entre inúmeros aspectos, no uso da representação do judeu típico pela propaganda política de Goebbels. Mas o que me interessa especialmente reter, nesse comentário suplementar de Derrida, é a suposição de que seria vão e sem pertinência, aos olhos de Benjamin, todo processo jurídico do nazismo e de suas responsabilidades, do momento em que o aparelho de julgamento ainda se desenvolvia sob a ótica do representável em sua objetivação histórica (Derrida, 2007, p. 137, 141142).

Há, portanto, nessa reflexão, um impasse que desafia a nossa própria capacidade de julgamento, conforme o julgamento se move num campo de linguagem ligado à representação. Toda tentativa de representar a realidade da violência estaria, em princípio, fadada ao fracasso, do momento em que a própria relação com a linguagem representativa já se encontra comprometida com a violência de sua submissão ao uso instrumental. É como se o exercício da violência já estivesse presente na possibilidade mesma do uso ordenado que fazemos da linguagem, em sua tentativa de denunciá-la. Para entender, portanto, o que significa servir-se da linguagem para se posicionar diante da violência de uma ordem hegemônica, cabe, antes, esclarecer que o próprio recurso da linguagem já se encontra comprometido com algum tipo de restrição normativa imposta violentamente, que, em Benjamin, identifica-se a seu uso representativo e instrumental.

Mas embora tudo pareça indicar que o uso da linguagem esteja direcionado e limitado por alguma espécie de ordenação representativa, sabemos, por outro lado, que a linguagem, por si só, não está limitada por esse modo de ordenação. A linguagem se revela antes, conforme assinala Pierre Bourdieu, como um "primeiro mecanismo formal cujas capacidades gerativas são ilimitadas", no sentido em que não há nada que não se possa dizer e que se pode dizer o nada (Bourdieu, 1982, p. 20). Se Chomsky nos lembra, por um lado, que é possível enunciar proposições absolutamente desprovidas de sentido, mantendo-se nos limites formais da gramaticalidade (vide o célebre exemplo Colourless greens sleep furiously), Frege nos ensina, por sua vez, que as palavras podem ter sentido sem comportar nenhum vínculo representativo para com o referente.

O que nos autoriza a falar, portanto, de um efeito que a psicanálise nomeia de forclusão generalizada no nível da linguagem, coextensivo ao que nela se propõe como uma "clínica universal do delírio", segundo a expressão forjada por Jacques-Alain Miller com base em Lacan, é a constatação de que o rigor formal da linguagem, quando muito, mascara, mas, na verdade, não impede o 
seu desvario semântico nem tampouco seu desligamento para com o referente. A língua, como sistema puramente diacrítico, não se encontra, como tal, vinculada à identidade do referente que regula seu uso na comunicação (Miller, 1996, p. 190-200). Disso resulta que a articulação representativa ou instrumental da linguagem para com o referente depende, para constituir-se, da submissão a algo que não está dado na própria linguagem, pelo qual se institui, em posição de exceção, a eficácia do significante mestre. De sorte que, quando Lacan denuncia a presença do mestre no horizonte do discurso ontológico, ali reconhece a referência ao ser como efeito de uma prescrição normativa. É preciso admitir, para se representar a realidade por meio da língua, o gesto normativo suplementar que institui, pelo significante mestre, o laço, de outro modo ausente, entre a linguagem e o referente. A ordenação representativa do referente pelo significante deriva, por conseguinte, de um princípio que só pode se exercer se não for questionado pelo sujeito. Trata-se de um princípio que deve ter inquestionavelmente razão, de cuja violência inquestionável depende a própria possibilidade de julgamento factual sobre a verdade e o erro.

\section{Ideologia e representação}

Podemos, portanto, inferir, a propósito do mecanismo de dominação ideológica, que ele é possível pelo simples fato de que toda realidade representada é invariavelmente uma realidade forçada, uma realidade, enfim, determinada por um elemento em posição de exceção que nela mesma não se deixa explicitar. Mas o que dizer então da posição que a psicanálise adota em relação ao problema da ideologia, tanto no que diz respeito à perspectiva que ela oferece para se pensar o mecanismo ideológico quanto à percepção que se tem, ou que se pode ter, da psicanálise, como prática comprometida com algum tipo de ideologia?

Digamos que, a princípio, do mesmo modo que o materialismo dialético, entendido como teoria crítica da ideologia, visa a explicitar as contradições que a ideologia oculta na representação da realidade que por ela se propõe, a psicanálise almeja, por sua vez, expor na discordância do sintoma, a verdade sonegada na relação do sujeito ao desejo, verdade de cuja sonegação depende a própria estabilidade de sua representação imaginária como Ego. Mas é preciso, antes de tudo, indagar, e esse é um dos principais pontos que eu gostaria de desenvolver aqui, por qual seria o estatuto da própria crítica da ideologia, no sentido de saber como e até que ponto essa atitude encontra-se ou não imune às relações de poder que ela visa a denunciar, assim como os meios dos 
quais ela dispõe para revelar a verdade que a ideologia oculta. É justamente a esse propósito que me parece pertinente convocar a psicanálise, no intuito de explicitar como se pode, por ela, interpelar tanto a ideologia quanto a crítica do discurso ideológico.

Sabemos que a psicanálise interpela a ideologia, quando sua experiência aborda os efeitos clínicos gerados pelo ocultamento da verdade que a ideologia impõe sobre o indivíduo. Pois se, do ponto de vista do materialismo histórico, o sujeito se encontra representado pelo seu pertencimento às classes sociais, a ideologia vem gerar a percepção da classe como uma entidade autônoma, fora do processo histórico, fazendo com que o indivíduo se sinta não como seu realizador, mas como estando a ela submetido. Sabemos, por outro lado, que, se a psicanálise surge numa situação gerada pelo mecanismo ideológico de controle disciplinar, ela vem responder justamente ao mal-estar decorrente da dificuldade experimentada pelo sujeito em se submeter ao dispositivo classificatório que esse controle lhe impõe.

Não foi por acaso, já o comentamos em outros momentos, que a psicanálise surgiu pela consideração da histeria, ou seja, da doença inclassificável pela qual se expõe, em sua apresentação cindida, a relação que o sujeito mantém com a verdade de um desejo incompatível com sua representação. É justamente por operar com essa verdade que advém à psicanálise o mérito de revelar, no interior do próprio sujeito, os mecanismos de desconhecimento que a crítica marxista atribuía ao funcionamento ideológico. Esses mecanismos de desconhecimento, que, na ideologia, funcionam como pontos de lacuna dos quais dependem sua própria coerência, para a psicanálise, revelamse na forma de um desconhecimento ativo, de um não querer saber que o sujeito opõe a toda representação pulsional que se revele incompatível com a unidade imaginária do ego. É nesse sentido que, aos olhos de Freud, é possível explicar a maneira hostil com que a sociedade reagiu à sua descoberta. Ao expor a incompatibilidade do desejo para com os ideais morais erigidos pela sociedade vitoriana, a psicanálise provoca uma recusa passional desprovida de qualquer tipo de exame crítico, que se estenderia até mesmo ao campo dos representantes do conhecimento científico.

Mas por que causa tanta estranheza que tal recusa ideológica provenha do discurso da ciência? Acaso deveríamos dali esperar, como chegou a pensar Althusser, uma relação ao conhecimento isenta de toda contaminação ideológica? ${ }^{1} \mathrm{O}$ que dizer, aliás, da própria teoria crítica da ideologia? Seria afinal possível sustentar a ideia, presente no horizonte da crítica ideológica,

A esse respeito, ver Althusser (1967, p. 145). 
de um sujeito original do conhecimento a ser alcançado mediante uma depuração contínua dos desvios que a ideologia imprime em sua faculdade de conhecer?

Se formos simpáticos com o ponto de vista de Nietzsche, de "A verdade e a mentira no sentido extramoral", nossa tendência seria, é claro, a de afirmar que não. Não existe, para Nietzsche, sujeito original do conhecimento nem tampouco instinto dessa natureza, enquanto, para ele, o próprio conhecimento é fruto de um embate político. É, aliás, por isso, observara Foucault, que, no lugar de falar da origem (Ursprung) do conhecimento, Nietzsche preferia falar de uma Erfindung, ou seja, de um artifício ou invenção do conhecimento, estabelecendo a sua própria existência como condicionada por um jogo de relaçôes sociais (Foucault, 2001, p. 14-21). Nesse sentido, as condiçōes ideológicas determinadas pelas relações de poder seriam fonte e não entrave ao conhecimento.

Essa leitura nos coloca, portanto, diante de um segundo paradoxo mais complicado talvez do que o primeiro: assim como não podemos falar da violência da representação sem nos servirmos de um discurso representativo, não nos é dado tampouco conhecer a verdade por detrás de sua deturpação ideológica, se concedermos - com Nietzsche e Foucault - que a própria ideologia se estabelece como solo mesmo de constituição do conhecimento. Nada mais ideológico, aliás, do que a pretensão da crítica da ideologia em aceder a um lugar isento dos efeitos ideológicos do saber. Se considerarmos, então, junto a P. Ricoeur, que a ideologia é um fenômeno insuperável da existência social, no sentido em que todo agrupamento humano necessita de uma representação para se manter (Ricoeur, 1977, p. 66), não haveria como aceder a um observatório exterior desde onde se possa vislumbrar o lugar no qual seu mecanismo opera. A saída da ideologia nos conduz, tal como ocorre numa garrafa de Klein, para dentro dela. Zizek nos oferece uma ampla série de exemplos que nos demonstram, à exaustão, essa impossibilidade de sair da garrafa de Klein ideológica (Zizek, 2007, p. 7-13).

Assim, um processo ideológico típico consiste em atribuir uma necessidade superior a uma situação historicamente delimitada e contingente: a contingência do real é provida de sentido pela ideologia, como quando se diz que a desigualdade social é uma condição inerente ao funcionamento da sociedade. Mas a ideologia também opera no sentido inverso quando toma a necessidade como uma contingência insignificante, tanto no tratamento psicanalítico, quando se diz que o ato sintomático foi um erro sem sentido, quanto, na economia, ao reduzir, por exemplo, a crise ao resultado de uma ocorrência externa, como se ela não fosse o fruto da própria organização do 
sistema. Existe, por outro lado, a mistificação ideológica que nos conduz a evocar a "complexidade da situação" para nos livrar da responsabilidade de agir. Mas a ideia de um sujeito responsável, livre para decidir, igualmente atende à necessidade ideológica de esconder a complexidade da trama em cujo contexto se insere o ato praticado pelo sujeito, e também definem, de antemão, as coordenadas de seu sentido. O sistema só pode funcionar se a causa de sua disfunção for situada na culpa do sujeito responsável, como ocorre quando o FMI acusava as assim chamadas economias emergentes de não terem realizado o dever de casa (leiam-se: as diretrizes do Consenso de Washington).

O fato é que não dispomos de meios para produzir, no que tange à descrição da realidade, nenhum tipo de representação ideologicamente neutra. Se a representação oficial do mapa-múndi, com a Europa acima da África, é flagrantemente ideológica, a representação inversa, com a África acima da Europa, não o seria menos. Impossível evadir-se dessa garrafa de Klein. O que sua topologia nos demonstra é que a ideologia reside ora na distorção da racionalidade, ora na própria crença referida a uma racionalidade que não esteja permeada por alguma estratégia de poder. Não se pode criticar a ideologia de fora da realidade por ela determinada, como pretendia Sartre, em sua recusa provocativa do prêmio Nobel. Parece-nos inapelavelmente ilusória a definição sartreana do intelectual como aquele que se mete com o que não é da sua conta, como alguém capaz de emitir juízos críticos sobre os diversos modos de exercício do poder. Todo discurso depende, para se constituir, de sua conformação a algum tipo de exercício do poder, e isso também se aplica ao discurso do intelectual. Mas a atitude cética que consiste em resignar-se à garrafa de Klein, em dizer que não se pode sair da ideologia e aceitar que todas as realidades não passam de jogos ficcionais, termina, por sua vez, por constituir o conformismo ideológico por excelência. Donde, aliás, explica-se que frequentemente os escritores céticos, como Hume ou Pirandello, tenham assumido posiçôes políticas conservadoras.

\section{O espectro da ideologia}

Da impossibilidade, diagnostica Zizek, de se constituir um observatório externo para localizar o ponto no qual se exerce a dominação ideológica deriva sua aparição espectral que tanto interessou a Jacques Derrida. Por carecer desse ponto de localização, a ideologia se espectraliza. A aparição do inaparente de que fala Derrida (Derrida, 1993, p. 238), a propósito da relação ao poder, diz justamente respeito ao espectro da ideologia como aparição destinada a ocultar 
as contradiçóes internas da realidade sobre a qual o seu objeto transparece. Tal é o caso do fetichismo da mercadoria, o qual implica a insólita espiritualização do corpo da mercadoria para apagar, de sua percepção, as relações de poder envolvidas em sua produção.

Se podemos, contudo, dizer, na esteira de Zizek, que a psicanálise nos permite ir além dessa perspectiva espectral, é conforme ela nos instrui que o espectro como tal já é uma defesa, um recuo de algo para o qual a própria ideologia seria a resposta sintomática (Zizek, 2007, p. 26). Esse algo, ao qual a dominação ideológica responde, e do qual depende, reciprocamente, o consentimento subjetivo à dominação ideológica - no sentido, proposto por La Boétie, da servidão voluntária -, esse algo está referido ao fato de que não há realidade sem espectro. Não há realidade sem espectro, no sentido em que não se pode cobrir inteiramente o real com o simbólico. A aparição espectral vem preencher justamente o furo do real, produzindo o seu ocultamento necessário para que uma realidade surja. O espectro ideológico germina, portanto, do esforço de se cobrir a cisão provocada pelo real sobre o simbólico, mediante a legitimação da crença que encobre a violência do poder, fornecendo-lhe o elemento batizado por Pascal de fundamento místico de sua autoridade.

O que está de fato em questão, nessa cisão provocada pelo real sobre o simbólico, diz respeito ao ponto do impasse, indicado por Lacan, do qual emerge não propriamente a dimensão da liberdade, como quer Zizek, mas o problema do ato e da decisão. Se, para Lacan, o analista tem horror do seu ato, assim como o sujeito recua com pavor espectral diante da decisão, é porque tanto um como outro o colocam na mira de uma situação sobre a qual não existem meios de deliberação ou consulta, situação sobre a qual, no entanto, é preciso se posicionar. O que se teme, no fundo, não é o espectro. O espectro é, antes, uma proteção contra algo mais apavorante: a decisão que não se garante mais pelo encadeamento estruturalmente ideológico do sentido prescrito pelo significante mestre. Essa consideração do furo a ser vedado pela ideologia que leva Lacan a dizer, a propósito da metafísica, em sua "Introdução à edição alemã dos escritos", que ela passa seu tempo tentando tapar o furo da política (Lacan, 2001, p. 555).

É no lugar, portanto, desse furo irredutível do real, que a ideologia busca tapar, como limite inerente que impede a sociedade de se constituir como totalidade fechada que a psicanálise deve intervir. Zizek chega a dizer que o marxismo, por não ter dado a esse furo o tratamento conceitual devido, termina por vê-lo retornar como efeito de uma ontologização do espectro, seja na forma do culto à personalidade do líder que desembocou no stalinismo, seja mesmo na forma do messianismo que em W. Benjamin se encarna, 
misticamente, na manifestação redentora da violência divina. Se a psicanálise, para tratar conceitualmente esse furo, teve que num certo momento se valer, ainda que precariamente, da teoria mítica da horda primitiva encabeçada pelo líder, é por perceber que em resposta a esse furo se constituiu, em posição de exceção, a dimensão social da soberania (Zizek, 2007, p. 34).

\section{$4 \mathrm{O}$ problema da exceção soberana}

Por esse motivo, sustentamos, em certo sentido, que a teoria do jurista Carl Schmitt, em que pese seu comprometimento execrável com a ideologia nazifascista, interessa mais à psicanálise do que a doutrina do jurista liberal Kelsen, malgrado a simpatia pessoal de Freud por este último. É em Schmitt, e não em Kelsen, que encontramos a definição do soberano como aquele que decide sobre o estado de exceção, em resposta ao caso para o qual a deliberação ou a consulta técnica ao saber da situação não têm nenhuma validade (Schmitt, 2006, p. 8-15)2. Sendo o caso dito excepcional, a própria manifestação do furo do real por não caber, em sua exposição concreta, no âmbito das situaçôes regidas pela norma geral, o soberano, em contrapartida, por ser aquele que decide sobre o estado de exceção, não pode ter, tampouco, sua definição inferida a partir do caso normal. A decisão que o constitui, em seu significado autônomo, não pode ser deduzida do conteúdo de uma norma.

O tratamento conceitual da dimensão de exceção soberana, como resposta aos efeitos da incidência do real sobre o simbólico, deveria assim nos permitir evitar o seu recobrimento espectral conforme nos convoca a pensá-la do ponto de vista de uma decisão que ao real responde. Trata-se de uma decisão que aplica a lei, dela se desaplicando, para retomarmos uma expressão cara a Carl Schmitt. No que diz respeito à clínica psicanalítica, usualmente atribuímos à posição do Pai essa dimensão soberana, no sentido em que ele "normalmente" suporta a função de exceção, desaplicando-se da norma que sua decisão engendra. Mas no lugar de se conceber o Pai como vetor de uma função lógica que responderia à incidência do real sobre o simbólico, o que se verifica, tanto entre muitos autores da clínica psicanalítica quanto em várias teorias que da psicanálise se valem, é a tendência, que visamos a questionar, de se lhe atribuir as propriedades imaginárias plenas do poder impositivo.

O modo, aliás, mais comum e, por que não dizer, ideológico, de se pensar essa dimensão da soberania, como lugar de resposta à incidência traumática

\footnotetext{
${ }^{2}$ A propósito da acuidade decisionista de C. Schmitt, leia-se "Sur Carl Schmitt" (Miller, 2003, p.256-269), aqui p. 263.
} 
do real sobre o simbólico, consiste, a bem dizer, em fazer apelo ao imaginário, no sentido, agora comentado, de conceber a instância soberana segundo os predicados da plenitude. Dessa concepção deriva a adesão de Carl Schmitt ao hitlerismo, assim como a analogia, por ele proposta, em sua Teologia Política, que situa o milagre como sendo o caso excepcional e Deus como princípio de intervenção soberana, soberania cuja função, no modelo familiarista, estaria representado pelo poder paterno. A referência canônica desse dispositivo imaginário é quase que invariavelmente o direito romano, sobre o qual a cultura ocidental constituiu o discurso do direito.

Numerosas são também as teses que se valem do postulado imaginário relativo à plenipotência da exceção soberana, as quais habitualmente concebem o mal-estar contemporâneo como um fenômeno decorrente do declínio progressivo do poder paterno. Tanto a tese de Pierre Legendre, que se refere ao desencadeamento coletivo da psicose na modernidade como corolário de uma carência crescente do pai quanto às formulaçôes que, hoje em dia, concebem as formas de manifestação das patologias atuais como efeitos decorrentes da perda da baliza paterna, apoiam-se numa mesma tendência de se condicionar a eficácia de sua posição soberana à plenitude imaginária do seu poder.

O fato é que dessa orientação não escaparia, por um certo período, nem mesmo o jovem psiquiatra Jacques-Marie Émile Lacan, leitor confesso de Émile Durkheim. Fica claro que a percepção lacaniana do mal-estar contemporâneo, descrita nos complexos familiares, de 1938, como fenômeno decorrente contração da família patriarcal ao talo reduzido do laço conjugal, encontra sua fonte nos cursos ministrados por Durkheim em 1892 (Lacan, 2001, 27 e passim). O pai moderno nitidamente aparece, numa relação comparativa ao grande patriarca antigo, como uma figura singularmente deficiente, tanto aos olhos de Durkheim quanto do Lacan durkheimiano, ocupando, assim, para retomarmos uma expressão de Deleuze, o lugar das essências desfalecentes, desde onde se renovam os apelos nostálgicos para restaurar-lhe o sentido eminente do qual o homem moderno teria se distanciado.

Mas o fato, salientado com grande pertinência por M. Zafiropoulos, é que os estudos da escola de Cambridge viriam demonstrar amplamente, a partir de 1970, que a forma conjugal da família nem de longe corresponde a um fenômeno moderno ${ }^{3}$. Sua existência remonta a antes do século XVI e, mesmo na Roma antiga, a quem os adeptos do patriarcado sistematicamente se referem, a forma conjugal da família foi igualmente predominante. A tese,

\footnotetext{
É indispensável ao leitor interessado pelo tema a leitura dos capítulos 4 e 5 intitulados, respectivamente, "La ruine de Durkheim", e "La ruine de la loi de la contraction familiale" (Zafiropoulos, 2001, p. 147-184). Uma versão mais resumida dessa discussão, traduzida em português, encontra-se disponível na revista Estudos Lacanianos, n. 3, agosto de 2009.
} 
portanto, relativa aos benefícios sociais do patriarcado e dos efeitos nefastos de seu declínio conjugal, longe de ser objeto de um estudo científico, revela-se, no final das contas, como uma fantasmagoria do pensamento de Durkheim.

Por esse motivo, interessa-nos enfatizar, seguindo ainda a leitura do livro de M. Zafiropoulos, que o Lacan que propõe um retorno a Freud, a partir de 1951, é um Lacan essencialmente distanciado da fantasmagoria patriarcal de Durkheim. O Lacan do retorno a Freud é, antes de tudo, um Lacan essencialmente influenciado pelo estruturalismo, cujas leituras de Jakobson e de Claude Lévi-Strauss lhe permitiram conceber, de maneira radicalmente distinta, o estatuto da função de exceção. Para entender isso, vale lembrar que, se o espectro ideológico se manifesta, como foi dito mais acima, na impossibilidade estrutural de se recobrir o real pelo simbólico, essa mesma impossibilidade se encontra examinada no fato da inadequação, indicada por Lévi-Strauss em sua "Introdução à obra de M. Mauss", entre o significante e o referente que se busca significar. Porém, o que a leitura estruturalista de Lévi-Strauss nos permite perceber a esse respeito é que a potência do significante mana, em dar conta dessa inadequação, potência sem a qual o pensamento simbólico não se poderia exercer, reside não em sua plenitude, mas em seu essencial esvaziamento de símbolo em estado puro, ou seja, em seu valor simbólico zero. Trata-se de um significante que gera a possibilidade de um discurso significativo enquanto ele próprio não comporta nenhum tipo particular de significação (Lévi-Strauss, 2003, p. 43). É nesse sentido que podemos identificá-lo ao elemento de exceção que organiza a possibilidade de um discurso deliberativo, desde que não seja alvo, ele próprio, de nenhum tipo de deliberação.

Se o Lacan do retorno a Freud é, pois, como enfatiza M. Zafiropoulos, um Lacan profundamente marcado pelo estruturalismo, ele o é quando o pensamento estruturalista foi efetivamente o instrumento que lhe permitiu emancipar da formulação falaciosa do patriarca durkheimiano, ou seja, da plenipotência imaginária da função de exceção. Foi somente em posse dessa leitura da função do significante mana, extraída de LéviStrauss, que Lacan pôde finalmente encontrar a tese, fundamentalmente freudiana, que localiza a função de exceção, fora de toda referência à plenitude imaginária do pai, no esvaziamento simbólico do pai morto. $\mathrm{O}$ pai morto, como suporte da função simbólica, designado pelo significante do nome do Pai do qual depende a operação de capitonagem essencial aos efeitos de significação, é, antes de tudo, um significante insignificante, 
um significante cuja eficácia depende justamente do esvaziamento de todo conteúdo significativo (Lacan, 1994, p. 307).

No lugar, portanto, do patriarca plenipotente das fantasmagorias nostálgicas que nutriam a tese de Émile Durkheim, temos, com o estruturalismo, que a exceção depende, para funcionar, não mais da manifestação plena do seu poderio, mas do seu apagamento no campo que ela organiza, denotado em Lacan pelo matema $S$ (A barrado). Esse significante de exceção, sem o qual os demais significantes nada representariam para o sujeito, nada mais é do que um traço que se traça de seu círculo sem poder ali ser contado, simbolizável pela inerência do - 1 em relação ao conjunto dos significantes (Lacan, 1966, p. 819). A exceção, para funcionar, deve, antes de tudo, poder se apagar, como já intuíra o legislador Sólon, na Grécia antiga, que, ao ser convocado a agir numa situação de exceção, prontificou-se se ir embora após instaurar a decisão reguladora.

\section{Referências}

Althusser, L. (1967). Análise crítica da teoria marxista. Rio de Janeiro: Zahar. Benjamin, W. (1988). Walter Benjamin Ângelus Novus. Frankfurt: Surkamp.

Bourdieu, P. (1982). Ce que parler veut dire. Paris: Fayard.

Derrida, J. (1993). Spectres de Marx. Paris: Galilée.

Derrida, J. (2007). Força de lei. São Paulo: Martins Fontes.

Foucault, M. (2001). A verdade e as formas jurídicas. Rio de Janeiro: Nau.

Lacan, J. (1966). Écrits. Paris: Seuil.

Lacan, J. (1994). Le séminaire - livre IV: La relation d'objet (1956-1957). Paris: Seuil.

Lacan, J. (2001). Autres écrits. Paris: Seuil.

Lévi-Strauss, C. (2003). Introdução à obra de Marcel Mauss. In: M. Mauss. Sociologia e antropologia. São Paulo: Cosac Naify.

Miller, J.-A. (1996). Matemas I. Rio de Janeiro: Jorge Zahar. 
Miller, J.-A. (2003). Le neveu de Lacan. Paris: Verdier.

Ricoeur, P. (1977). Interpretação e ideologias. Rio de Janeiro: Francisco Alves.

Schmitt, C. (2006). Teologia política. Belo Horizonte: Del Rey.

Zafiropoulos, M. (2001) Lacan et les sciences sociales. Paris: PUF.

Zizek, S. (2007). O espectro da ideologia. In: Zizek, S. (organizador). Mapa da Ideologia. Rio de Janeiro: Contraponto. 